\title{
College Student Exercise Motivation: The Role of Belongingness and College Self-Efficacy
}

\author{
Bini B Sebastian ${ }^{1}$, Christopher D Slaten ${ }^{1}$, Michael Steven Williams ${ }^{1}$, Zachary M. Elison ${ }^{2}$ \\ ${ }^{1}$ University of Missouri-Columbia, USA \\ ${ }^{2}$ University of North Carolina-Charlotte, USA \\ Correspondence: Christopher D Slaten, University of Missouri-Columbia, USA.
}

Received: April 23, 2021

doi:10.11114/ijce.v4i2.5221
Accepted: May 25, $2021 \quad$ Online Published: May 27, 2021

URL: https://doi.org/10.11114/ijce.v4i2.5221

\begin{abstract}
This study examined the role of college self-efficacy in the relationship between university belongingness and exercise motivation among a group of college students $(N=311)$. Multiple social factors have been identified as playing an important role in students' physical health and wellness (Leslie et al., 1999; Wallace et al., 2000); however, the mechanisms by which university belongingness influences various exercise motives are unexplored. In the current study, college self-efficacy was examined as a mediator between university belongingness and six types of exercise motivation: stress management, appearance, enjoyment, revitalization, weight management, and positive health (Markland \& Ingledew, 1997). Results showed that college self-efficacy mediated the relationship between belongingness and exercise motivation for stress management, enjoyment, revitalization, and positive health. These findings highlight how college self-efficacy helps explain the relationship between university belongingness and motivation to exercise, providing insight into prevention research and implications for university personnel to help foster greater health promotion on campus.
\end{abstract}

Keywords: university belongingness, college self-efficacy, college student health, exercise motivation

\section{Introduction}

College students experience both academic and non-academic stressors that influence their ability to effectively navigate higher education (Perry et al., 2001). During the transition into college, students attempt to manage new responsibilities, coursework, varied schedules, and a new living environment (Gall et al., 2000), which can create barriers to students' academic success. Moreover, students may engage in unhealthy behaviors or resort to maladaptive coping mechanisms as a way of managing stress during this transitional period. For example, studies show college students to be at a greater risk for decreased physical activity, increased emotional stress, and illicit drug use (Bray \& Born, 2004; Dennhardt \& Murphy, 2013). Researchers have conducted empirical studies to examine certain factors that may buffer against psychological distress for college students and physical activity stands out as one of the most effective (Lowry et al., 2000; Suminski et al., 2002; Brown \& Blanton, 2002; Haskell et al., 2007).

The benefits of exercise include improved physiological health, healthy weight management, increased self-esteem, lower risk for anxiety and depression, improved PTSD symptoms, adequate sleep, positive perception of general health, and fewer risky behaviors including binge drinking, physical fighting, and multiple sexual partners (Buckworth \& Nigg, 2004; Dinger, Brittain, \& Hutchinson, 2014; Furia, Lee, Strother, \& Huang, 2009; Lowery et al., 2005; Moor, et al. 2008; Penedo \& Dahn, 2005; Rutter et al., 2013). The American College Health Association-National College Health Assessment II (2017) reported that $21 \%$ of all students do not exercise at all, $58 \%$ exercise $1-4$ days a week, and $21 \%$ of students exercise 5-7 days per week. Based on these rates, $79 \%$ of college students fail to meet the recommended guidelines for weekly physical activity. Given such a disparity, it is important for researchers to identify and understand motivations behind exercise, as there may be implications for improved student health, academic success, and retention. Although scholars have attempted to identify contributing factors to exercise motivation, there has been little attention given to psychosocial factors.

In order to identify factors that influence college student health and overall achievement, researchers may consider adopting a holistic approach that include social factors in their investigations. College student belongingness is an understudied social phenomenon as it relates to student health, even though belonging has been linked to a plethora of 
other positive outcomes including higher GPA, student retentions, and student achievement (Goodenow 1993; Tao et al. 2000; Wolf et al., 2017). The theory of belongingness provides a framework for understanding how college student psychosocial health and the motivational factors that influence overall academic achievement. Students' motivation to engage in physical activity is a robust predictor of their willingness to initiate an exercise routine and adhere to a long-term exercise plan (Teixeira et al., 2012). Researchers should examine how college student exercise motivation is related to overall psychosocial well-being. Therefore, the current study will utilize self-determination theory to examine a mediational relationship among belongingness, college self-efficacy, and various types of exercise motivation. The outcomes of this study may benefit both physically active and sedentary college students.

\section{University Belongingness}

Belongingness has been shown to be one of the strongest predictors of academic achievement among college students (Hausmann et al., 2007; Gummadam, Pittman, \& Ioffe, 2016; Strayhorn et al., 2016; Zumbrunn et al., 2014). Generally, the sense of belonging can be described as a human drive for ongoing, supportive, and positive interpersonal relationships (Baumeister \& Leary, 1995). This sense of connectedness is a subjective perception rooted in the belief that an individual is an essential part of a group, community, or organization. Belongingness is especially important in the university settings because it may help with the cultivation of healthy academic behaviors and serve as a buffer against academic stress (Civitci, 2015). In academic settings, belongingness refers to their connection to campus, commitment to their institution, and perception that their abilities are recognized by others (Slaten, 2017).

In addition to academic achievement, college students' sense of belongingness on campus has been found to influence academic adjustment, motivation, retention, and success (Goodenow 1993; Han, Farruggia, \& Moss, 2017; Hoffman, Richmond, Marrow, \& Salomone, 2002; Slaten et al., 2014; Slaten et. al., 2016; Tao et al. 2000). Although there is debate about the operational definition of belongingness overlapping with that of social support, the framework of belongingness may allow for an understanding of specific characteristics related to the perception of connectedness and commitment in educational settings. Tinto (1975) theorized that academic and social engagement are closely linked to students' sense of belonging on campus. Tinto's model of student integration posits that students are more likely to graduate when socially integrated into campus, thus increasing their general commitment to the university. Academic belonging has been found to protect against negative mental health factors such as depression, stress, perceived discrimination, and low-peer acceptance (Baskin et al., 2010; Hagerty et al., 1996; Huynh \& Gillen-O’Neel, 2016). The absence of this perceived social connectedness has been linked to psychological distress (Baumeister \& Leary, 1995), and feelings of loneliness in the academic setting have been found to increase risk for suicide, major depression and anxiety disorders (Eisenberg et al., 2007; Silverman, Meyer, \& Sloane, 1997).

\section{College Self-Efficacy}

Although few studies have examined the psychosocial benefits of belongingness on college campuses, even fewer studies have examined how students' sense of belonging encourages self-efficacy in the college environment (Walton et al. 2015; Walton \& Cohen 2007). The concept of self-efficacy was first introduced by Albert Bandura in 1977, and it has been defined as "the belief in one's ability to organize and execute courses of action that are necessary to accomplish a particular task" (Bandura, 1977; 1986). College self-efficacy is a domain specific measure of efficacy that refers to the degree of confidence students have for completing college-related tasks (Barry \& Finney, 2007). As such, campus environments may influence how students perceive their ability to succeed academically. Goodenow (1993) found that youth who felt a high sense of belonging to their school were more likely to be more academically motivated and believe that are able to succeed in college-related tasks. Micari and Pazos (2012) found that strong student-faculty relationships increased student confidence and achievement in difficult courses. Similarly, Freeman et al. (2007) found a positive relationship between first year college students' sense of class belonging and their subsequent academic self-efficacy, intrinsic motivation, and social acceptance. As students' relationship qualities strengthen, their willingness to put in effort in college related tasks and commitment to academic success grows accordingly. Examining factors that lead to academic achievement may yield information about how students can adopt a holistic approach to health. Researchers who study belongingness view this psychosocial construct as an instrumental part of not only academic success and mental health, but physical health as well, which includes exercise motivation.

\section{Exercise Motivation}

Although physical activity has been shown to improve overall health (Dunn, Trivedi, \& O'Neal, 2001), very little research has been conducted on the reasons behind college students' exercise initiation and the maintenance of healthy exercise behaviors. Research shows that physical activity among students tends to decrease from high school into college and even more so following college graduation (Calfas et al., 1994). Furthermore, 50\% of adults who begin an exercise regimen will terminate their routine within the first 6 months of participation (Wilson \& Brookfield, 2009; Matsumoto \& Tekenaka, 2004). Evidently, there are a number of reasons why students choose to participate in and maintain physical 
activity. Frederick and Ryan (1993) found that individuals who are physically active are motivated to exercise because they enjoy the activity, strive to achieve competence in the activity, or they desire to achieve a certain physical appearance. However, the extent to which individuals implement their regimen into their daily lives may differ. Li (1998) suggests that the antecedents of exercise motivation are directly related to the correlates and consequences of cognitive and behavioral processes. For example, the motivation to exercise for physical appearance and weight management is shown to help with the initiation of an exercise regimen among students (Markland \& Ingledew, 2007), and the motivation to exercise for physical health and enjoyment is related to exercise maintenance over time (Seguin et al., 2010; Huberty et al., 2008). Motivations to exercise for enjoyment and competence appear to play a central role in the maintenance of physical activity behaviors (Thogersen-Ntoumani, 2006). As such, it is imperative that scientists study exercise motivation that leads to exercise engagement and adherence over time. Studies on college student health may inform how universities help students foster a sense of belonging and encourage healthy behaviors among their student body.

\section{Self-Determination Theory as a Conceptual Framework}

Researchers have found that various types exercise motivation differentially impacts health outcomes; distinguishing these motives as either intrinsic or extrinsic motivation may be helpful in better understanding health effects (Deci \& Ryan, 1987; Markland, 1999; Markland \& Ingledew, 2007; Vartanian, Wharton, \& Green, 2011). Self-determination theory (SDT; Deci \& Ryan, 1985, 1990) is often used as a framework to examine the differential impacts of specific exercise motivations in terms of intrinsic and extrinsic motivation (Markland \& Ingledew, 2007). Intrinsic exercise motivation refers to exercising for internal rewards, personal interest, or enjoyment. Individuals who are extrinsically motivated tend to lack autonomy in their participation, focus on the achievement of an outcome, and are more likely to exercise to gain a reward or avoid punishment (Ryan \& Deci, 2000). Teixeira and colleagues (2012) created a general SDT process model for exercise behavior, adapted from the general health process model (Ryan \& Patrick, 2009). This general SDT process model establishes links among supportive exercise settings, autonomy, and exercise motivation, incorporating both psychosocial and health factors into an analysis of exercise behaviors. Markland and Ingledew (2007) have also applied SDT to examine exercise behaviors and their research has suggested that different participation motives influence motivation and engagement with different consequences for behavior. More specifically, they found that the motive to exercise for appearance and weight management increased external regulation, which reduced participation. Social engagement and health increased intrinsic regulation. Studies have also shown that people who participate in activities for intrinsic reasons are more likely to enjoy and persist in the activity (Ryan, et al., 1997), which may contribute to the maintenance of healthy exercise behaviors. Markland (1999) examined the difference between weight management, appearance, and health pressures (extrinsic motives) and enjoyment and affiliation (intrinsic motives) on the degree of autonomy for exercise. This study found that weight management and appearance were negatively related to autonomy and enjoyment was positively related to autonomy.

As self-determination theory considers associations among autonomy, motivation, and social factors, we hypothesize that a strong sense of belonging on campus may serve as a foundation for college students to build their college self-efficacy in an academic setting. Furthermore, we hypothesize that high levels of college self-efficacy will predict high levels of exercise motivation for intrinsic motivations. The six subtypes of exercise motivation include: stress management, appearance, enjoyment, revitalization, weight management, and positive health. Intrinsic motivations include stress management, enjoyment, revitalization, and positive health, and extrinsic motivations include appearance and weight management. Literature has shown intrinsic motivations to be related to personal fulfillment and reward, whereas extrinsic factors may be linked to pressure from external sources. Other studies have found intrinsic motivations for exercise to be an instrumental factor in the maintenance of healthy exercise behaviors, whereas extrinsic motivations may be important in the onset of or short-term maintenance of exercise (Deci \& Ryan, 1987; Frederick \& Ryan, 1993, 1995).

\section{The Present Study}

As SDT proposes autonomous motivation to be associated with adaptive outcomes (Deci \& Ryan, 2000), the sense of support from belongingness may allow students to believe they are capable of achieving academic success. Students' confidence in navigating their university life may influence their approach to health behaviors, such as exercise, in a way that is internally rewarding instead of externally inspired. Therefore, the current study will examine the potential mediating role of college self-efficacy on the relationship between college students' sense of belonging and intrinsic motivations to exercise. As the mediational approach suggests, we expect that the effect of belongingness on exercise motivation depends on the strength of college self-efficacy. More specifically, the following hypotheses are proposed: (1) Belongingness predicts exercise motivation for intrinsic exercise motivations: stress management, enjoyment, revitalization, and positive health. (2) Belongingness predicts college self-efficacy. (3) College self-efficacy predicts intrinsic exercise motivations: stress management, enjoyment, revitalization, and positive health. (4) College self-efficacy will mediate the relationship between belongingness and the intrinsic exercise motivation subtypes. As 
motives to exercise for physical appearance or weight management tend to be extrinsic motivations, results may be mixed for these variables.

\section{Method}

\section{Participants}

Participants included 311 undergraduate college students at a large university in the Midwestern United States. The students were given a demographic questionnaire created for this study that asked respondents to provide their age, race/ethnic identity, and year in school. The sample consisted of $21 \%$ males and $79 \%$ females with a mean age of 22 $(\mathrm{SD}=5.34)$. Of the participants, $72 \%$ identified as White, $16 \%$ as Asian, $4 \%$ as Hispanic, $4 \%$ Multiracial, $3 \%$ as African American, $<1 \%$ as American Indian, $<1 \%$ as Native Hawaiian or other Pacific Islander. The sample was made of $9 \%$ freshmen, $18 \%$ sophomores, $21 \%$ juniors, $21 \%$ seniors, and $18 \%$ graduate students. Of the students, $24 \%$ report to have a cumulative GPA of less than $2.0,22 \%$ report to have a GPA in the range of $2.0-3.0$, and $54 \%$ report to have a GPA greater than 3.0. Regarding exercise behaviors, $8 \%$ of students report no physical activity, $11 \%$ report to exercise once a week, $19 \%$ report to exercise twice a week, $29 \%$ report to exercise three times a week, $17 \%$ exercise four times a week, 11 exercise five times a week, and $6 \%$ of student report to exercise more than five times a week.

\section{Procedures}

Undergraduate students, ages 18 to 25 years old (i.e., traditional college age), currently enrolled in courses at the university site were eligible to participate in the study. After obtaining approval from the institutional review board, participants were recruited for this internet-based survey through a recruitment email sent by the registrar's office to 4,000 random undergraduate students who met study criteria. The recruitment email outlined the purpose of the study and contained a web link to the online survey. A follow-up email to the same potential participant pool was sent out a week later to encourage participation. As an incentive, participants were entered into a random drawing for a t-shirts and gym bags provided by the campus recreation center.

\section{Measures}

University Belonging. The University Belonging Questionnaire (UBQ; Slaten et al., 2017) is a 24-item scale that was employed to measure the sense of belonging on college campuses. This scale measures three factors related to university belongingness which are university affiliation, university support and acceptance, and faculty and staff relations. Examples of items on the UBQ include, "I believe I have enough academic support to get me through college," and "I would be proud to support my university in any way I can in the future." The UBQ had an internal consistency of .94, the university affiliation subscale had a Chronbach's alpha of .92, university support and acceptance with .85 , and faculty and staff relations with .88 .

College Self-Efficacy. The College Student Self-Efficacy Inventory (CSEI; Solberg et al., 1993) is a 20-item scale that measures the extent to which participants believe in their abilities to complete college-related tasks successfully (Solberg, O'Brien, Villarreal, Kennel, \& Davis, 1993). Items on this scale include statements such as "talk with your professors", "do well on exams", and "make new friends at college." Items ranged on a 10-point scale from 0 (not at all confident) to 9 (extremely confident). The internal consistency for this scale is $.83-.88$ for college students. The convergent and incremental validity for the CSEI has been shown to be negatively correlated with distress and positively correlated with adjustment and social integration (Solberg et al., 1998).

Exercise Motivation. A modified version of the The Exercise Motivations Inventory-2 (Markland \& Ingledew, 1997) was designed to assess responses to motives of exercising to assess intrinsic and extrinsic motivations to exercise. The instrument originally consists of 51 -items and 14 subscales; however, for the sake of the study only 22 -items were employed, examining the following subscales specifically targeting intrinsic and extrinsic subscales: positive health, enjoyment, revitalization, stress management, weight management, and appearance. Examples items include, "Personally, I exercise (or might exercise) to show my worth to others," or "Personally, I exercise (or might exercise) because I want to maintain good health." All items were rated on a 5-point Likert scale. The internal reliability for these subscales was between .84 and .94 .

\section{Design and Data Analysis}

Multiple regression analysis was used to test whether college self-efficacy mediated the relationship between belongingness and the six categories of exercise motivation, using the four-step method described by Baron and Kenny (1986). First, the independent variable must be predictive of the outcome variable. For the current study, belongingness much be significantly related to the six domains of exercise motivation: positive health, enjoyment, revitalization, stress management, weight management, and appearance. Next, the independent variable, university belonging, should predict the mediator, college self-efficacy. Then, the independent variable should be related to the dependent variable; therefore, belongingness should predict college self-efficacy. Lastly, the relationship between the independent variable and the 
dependent variable should decrease after the mediator is entered into the model. After the mediator is entered into the model, if the unstandardized beta weights of the independent variables are still statistically significant, a partial mediation is present. If the unstandardized beta weights of the independent variables are not significant, full mediation is present. The Sobel test will be applied to assess the statistical significance of the indirect effect of the mediator in each mediation model (MacKinnon et al., 1995; Sobel, 1982). This test determines the significance of the reduction in the effect of the independent variable on the dependent variable when the mediator is included in the regression.

\section{Results}

The correlations, means, and standard deviations for the measures employed in the present study are displayed in Table 1. To examine the mediation, we conducted hierarchical multiple regressions using Baron and Kenny's (1986) approach. First, we examined the relationship between belongingness as the independent variable and each of the six domains of exercise motivation as the dependent variable. A linear regression analysis was used to examine the influence of belongingness on each of the exercise motivation domains: stress management, revitalization, enjoyment, positive health, weight management, and appearance. Findings indicated that individuals with a high sense of belonging were more likely to be motivated to exercise for benefits related to stress management $(\beta=.78$, revitalization $(\beta=.87)$, enjoyment $(\beta=1.14)$, positive health $(\beta=.31)$, weight management $(\beta=.54)$, and appearance $(\beta=.37)$. Next, we regressed college self-efficacy onto belonging, and the relationship was found to be significant $(\beta=1.259)$. Then, we examined the possible mediation effect of college self-efficacy on the relationship between belongingness and each of the exercise motivation. In this step, we regressed each of the exercise motivation domains simultaneously on both belongingness and college self-efficacy, using six separate models. College self-efficacy was found to mediate the relationship between belongingness and the intrinsic exercise motivations: stress management, revitalization, enjoyment, and positive health. College self-efficacy did not mediate the relationship between belongingness and weight management or relationship between belongingness and the appearance. The mediating effects were verified with a Sobel test $(\mathrm{p}<0.001)$.

Table 1. Correlations, Means, and Standard Deviations for Belongingness, College Self-Efficacy, and Exercise Motivation

\begin{tabular}{lcccccccc}
\hline & 1. & 2. & 3. & 4. & 5. & 6. & 7. & 8. \\
\hline 1. Belonging & - & - & - & - & - & - & - & - \\
2. College Self-Efficacy & $.370^{* *}$ & - & - & - & - & - & - & - \\
3. Positive Health & $.181^{* *}$ & $.216^{* *}$ & - & - & - & - & - & - \\
4. Enjoyment & $.156^{* *}$ & $.277^{* *}$ & $.295^{* *}$ & - & - & - & - & - \\
5. Revitalization & $.174^{* *}$ & $.265^{* *}$ & $.392^{* *}$ & $.797^{* *}$ & - & - & - & - \\
6. Stress management & $.133^{* *}$ & $.288^{* *}$ & $.303^{* *}$ & $.544^{* *}$ & $.625^{* *}$ & - & - & - \\
7. Appearance & $.114^{*}$ & -.013 & $.393^{* *}$ & $.134^{* *}$ & $.144^{* *}$ & $.180^{* *}$ & - & - \\
8. Weight management & $.197^{* *}$ & .005 & $.406^{* *}$ & .077 & $.105^{*}$ & $.128^{* *}$ & $.707^{* *}$ & - \\
M & 3.20 & 7.89 & 5.49 & 4.30 & 4.78 & 4.65 & 4.83 & 4.97 \\
SD & .41 & 1.26 & .73 & 1.24 & 1.10 & 1.18 & 1.09 & 1.23 \\
\hline
\end{tabular}

** The correlation is significant at $\mathrm{p}<0.01$

* The correlation is significant at $\mathrm{p}<0.05$

Table 2. Hierarchical Regression of University Belonging on Exercise Motivation With College Self-Efficacy as a 
Mediator

B

Predictor: University Belonging

Mediator Model 1

Stress Management

College Self-Efficacy

\section{Mediator Model 2}

Positive Health

College Self-Efficacy

\section{Mediator Model 3}

Revitalization

College Self-Efficacy

\section{Mediator Model 4}

Enjoyment

College Self-Efficacy

\section{Mediator Model 5}

College Self-Efficacy

\section{Mediator Model 6}

Weight Management

College Self-Efficacy
Physical Appearance

.267

.049

$.083^{*}$

5.491

.031

$.062 *$

221

.045

$.083 *$

4.868

Note. College Self-Efficacy as mediator; Exercise Motivation as outcome variable.

** The correlation is significant at $p<0.01$

* The correlation is significant at $\mathrm{p}<0.05$

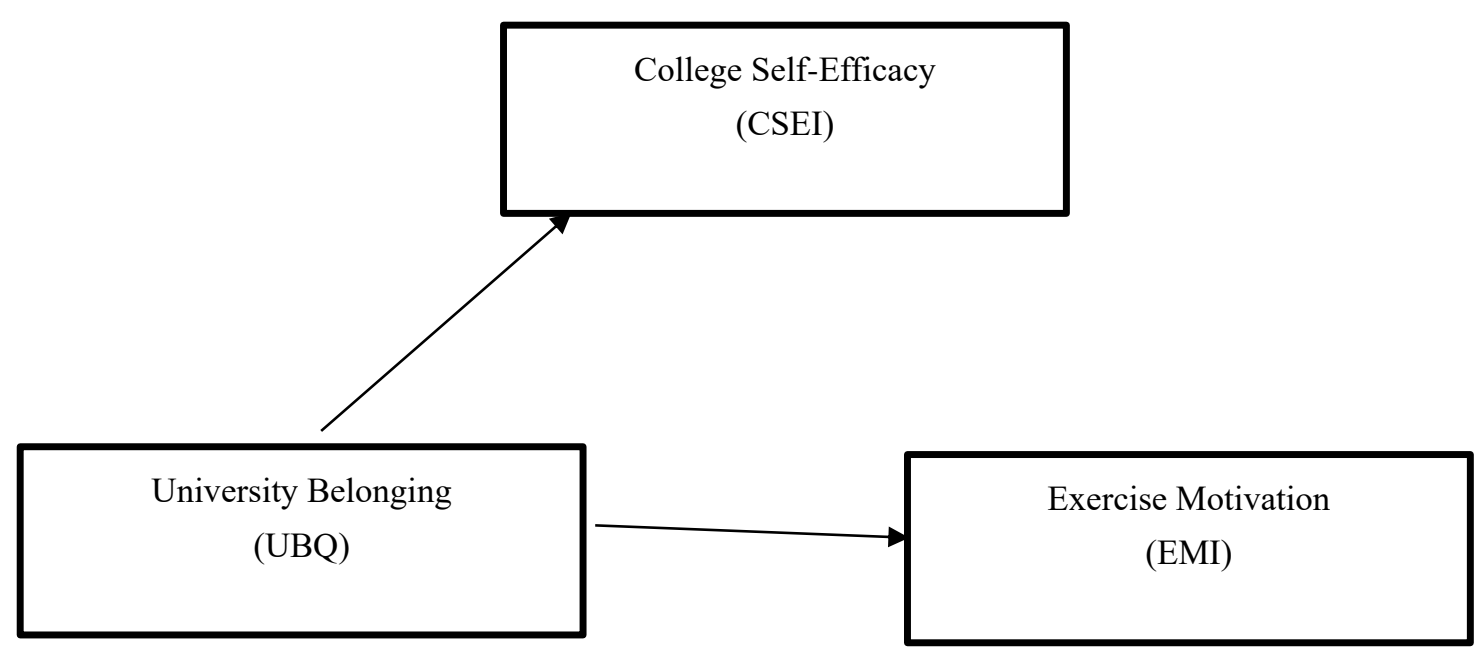

Figure 1. The Mediation Model

\section{Discussion}

The current study examined the relationship between university belonging, college self-efficacy, and exercise motivation for college students. The study used a multiple regression analysis to test the direct relationships between variables, as well as the hypothesized mediating effect of college self-efficacy. Findings suggest that college students 
who felt connected to their university were motivated to exercise for enjoyment, positive health, revitalization, and stress management. The meditation effect suggests that students' belongingness to their campus increase their exercise motivation through college self-efficacy, or their belief in their ability to accomplish college-related tasks. Surprisingly, college self-efficacy did not mediate the relationship between belongingness and the motivation to exercise for weight management or appearance. The mediation effect of college self-efficacy on the relationship between belongingness and intrinsic exercise motivation variables can be explained using SDT (Deci \& Ryan, 1985, 1990). College self-efficacy was found to mediate the relationship between belonging and the intrinsic exercise motivations. College self-efficacy did not appear to mediate the link between belonging and the extrinsic exercise motivations. Previous studies have found a similar pattern regarding extrinsic motivations in the context of SDT. For example, a study conducted by Homan and Tylka (2014), appearance-based exercise motivation was found to moderate the relationship between exercise frequency and positive body image, which highlighted that exercise frequency was associated with higher positive body image. However, high levels of appearance-based exercise motivation weakened the relationship between frequency and positive body image. Researchers concluded that the promotion of exercise motivation needs to de-emphasize weight loss and appearance for positive body image.

\section{Implications}

Educational institutions may be able to create an environment of inclusivity in which students may cultivate a sense of belonging that contributes to their psychosocial health and academic success (Karcher, 2004). In turn, this sense of belonging may strengthen students' commitment to the university as well as their belief in themselves to complete college-related tasks, or their college self-efficacy. The current study and previous empirical studies have found belongingness and college self-efficacy to influence physical activity among students, contributing to physical wellness and health promotion. Moreover, as the subtypes of exercise motivation seem to be impacted by psychosocial factors differentially, higher education may consider re-evaluating the way physical exercise is advertised and marketed to students from a preventative standpoint. For example, although extrinsic motives seem to help students implement a healthy exercise plan, intrinsic motivations seem to allow for the maintenance of such a regimen. Moreover, based on the results of the current study, it is possible that if campus recreation centers were to focus on more events that provide students with opportunities to engage in their facilities and foster a sense of belonging, students may then be more likely to exercise. Examples of these opportunities may include movie nights, dinners, and other events that allow students to engage in social activities with one another and provide entry into the recreation facility in a comforting way and encourage additional visits for exercise.

\section{Limitations and Future Directions}

Limitations. A few limitations should be noted when interpreting this research. The sample used in the current study was largely homogenous in ethnicity and gender, comprising of mainly Caucasian females, therefore not necessarily representative of the overall college student population. Further, the present study utilized a multiple regression to analyze the data, which allows us to infer how variables are related, but causality cannot be implied.

Future Research. Researchers may consider repeating this study with a different population make-up. As the sample used in the current study was largely homogenous, future researchers may consider using a more diverse sample in terms of gender and ethnicity. Exercise motivations have been found to vary across populations; therefore, researchers may consider examining the mediation model across a variety of populations. For example, Cho and Beck (2016) analyzed the differences in international students' motivation between students that participate in competitive physical activity and students that do not participate in competitive physical activity and found statistical differences in their motivation of affiliation, challenge, and competition between non-competitive and competitive physical activity among the study sample. Gender differences in exercise motivation have also been examined in that women have been found to be more motivated to exercise for managing their weight, whereas men were motivated by the challenge and appearance aspects (Egli et al., 2011). Researchers may also consider conducting a longitudinal study of college student self-efficacy and academic outcomes to physical activity. Longitudinal research may on this topic may help colleges identify factors that promote healthy behaviors among college student. The implications of the aforementioned studies may be enhanced through future research. As exercise motives have been related to type, extent, and stage of exercise participation (Frederick, Morrison, \& Manning, 1996; Frederick \& Ryan, 1993), researchers may further examine these factors in relation to belongingness and college self-efficacy in college students. This study observed college self-efficacy as a partial mediator between belongingness and certain, which implies there may be other variables that better explain the link between belongingness and exercise motivation among college students.

\section{References}


Bandura, A. (1977). Self-efficacy: toward a unifying theory of behavioral change. Psychological review, 84(2), 191. https://doi.org/10.1037/0033-295X.84.2.191

Bandura, A. (1986). The explanatory and predictive scope of self-efficacy theory. Journal of social and clinical psychology, 4(3), 359-373. https://doi.org/10.1521/jscp.1986.4.3.359

Baron, R. M., \& Kenny, D. A. (1986). The moderator-mediator variable distinction in social psychological research: Conceptual, strategic, and statistical considerations. Journal of personality and social psychology, 51(6), 1173. https://doi.org/10.1037/0022-3514.51.6.1173

Barry, C. L., \& Finney, S. J (2007, October). A Psychometric Investigation of the College Self Efficacy Inventory. Paper presented at the annual meeting of the Northeastern Educational Research Association, Rocky Hill, CT.

Baskin, T. W., Wampold, B. E., Quintana, S. M., \& Enright, R. D. (2010). Belongingness as a protective factor against loneliness and potential depression in a multicultural middle school. The Counseling Psychologist, 38(5), 626-651. https://doi.org/10.1177/0011000009358459

Baumeister, R. F., \& Leary, M. R. (1995). The need to belong: desire for interpersonal attachments as a fundamental human motivation. Psychological bulletin, 117(3), 497. https://doi.org/10.1037/0033-2909.117.3.497

Biddle, S. (1995). Exercise and psychosocial health. Research quarterly for exercise and sport, 66(4), 292-297. https://doi.org/10.1080/02701367.1995.10607914

Bray, S. R., \& Born, H. A. (2004). Physical activity and transition to university: Implications for health and psychological well-being. American Journal of College Health, 52, 181-188. https://doi.org/10.3200/JACH.52.4.181-188

Brown, D. R., \& Blanton, C. J. (2002). Physical activity, sports participation, and suicidal behavior among college students. Medicine \& Science in Sports \& Exercise. https://doi.org/10.1097/00005768-200207000-00006

Buckworth, J., \& Nigg, C. (2004). Physical activity, exercise, and sedentary behavior in college students. Journal of American College Health, 53(1), 28-34. https://doi.org/10.3200/JACH.53.1.28-34

Calfas, K. J., Sallis, J. F., Lovato, C. Y., \& Campbell, J. (1994). Physical activity and its determinants before and after college graduation. Med Exer Nutr Health, 3, 323-334.

Civitci, A. (2015). Perceived stress and life satisfaction in college students: Belonging and extracurricular participation as moderators. Procedia-Social and Behavioral Sciences, 205, 271-281. https://doi.org/10.1016/j.sbspro.2015.09.077

De Moor, M. H., Boomsma, D. I., Stubbe, J. H., Willemsen, G., \& Geus, E. J. (2008). Testing causality in the association between regular exercise and symptoms of anxiety and depression. Arc Gen Psychiatry, 65, 897-905. https://doi.org/10.1001/archpsyc.65.8.897

Deci, E. L., \& Ryan, R. M. (1987). The support of autonomy and the control of behavior. Journal of personality and social psychology, 53(6), 1024. https://doi.org/10.1037/0022-3514.53.6.1024

Dennhardt, A. A., \& Murphy, J. G. (2013). Prevention and treatment of college student drug use: A review of the literature. Addictive behaviors, 38(10), 2607-2618. https://doi.org/10.1016/j.addbeh.2013.06.006

Dinger, M. K., Brittain, D. R., \& Hutchinson, S. R. (2014). Associations between physical activity and health-related factors in a national sample of college students. Journal of American College Health, 62(1), 67-74. https://doi.org/10.1080/07448481.2013.849710

Dunn, A. L., Trivedi, M. H., \& O'Neal, H. A. (2001). Physical activity dose-response effects on outcomes of depression and anxiety. Medicine and Science in Sports and Exercise, 33(Supplement 6): S587-S597. https://doi.org/10.1097/00005768-200106001-00027

Egli, T., Bland, H. W., Melton, B. F., \& Czech, D. R. (2011). Influence of age, sex, and race on college students' exercise motivation of physical activity. Journal of American college health, 59(5), 399-406. https://doi.org/10.1080/07448481.2010.513074

Eisenberg, D., Gollust, S. E., Golberstein, E., \& Hefner, J. L. (2007). Prevalence and correlates of depression, anxiety, and suicidality among university students. Am $J$ Orthopsychiatry, 77, 534-542. https://doi.org/10.1037/0002-9432.77.4.534

Frederick, C. M., \& Ryan, R. M. (1993). Differences in motivation for sport and exercise and their relations with participation and mental health. Journal of sport behavior, 16(3), 124.

Frederick, C. M., Morrison, C., \& Manning, T. (1996). Motivation to participate, exercise affect, and outcome behaviors toward physical activity. Perceptual and Motor Skills, 82(2), 691-701. https://doi.org/10.2466/pms.1996.82.2.691 
Freeman, S., O'Connor, E., Parks, J. W., Cunningham, M., Hurley, D., Haak, D., Dirks, C., \& Wenderoth, M. P. (2007). Prescribed Active Learning Increases Performance in Introductory Biology. Cell Biology Education Life Sciences Education, 132-139. https://doi.org/10.1187/cbe.06-09-0194

Furia, A. C., Lee, R. E., Strother, M. L., \& Huang, T. T. (2009). College students' motivation to achieve and maintain a healthy weight. American Journal of Health Behavior, 33(3), 256-263. https://doi.org/10.5993/AJHB.33.3.4

Gall, T. L., Evans, D. R., \& Bellerose, S. (2000). Transition to first-year university: Patterns of change in adjustment across life domains and time. Journal of Social and Clinical Psychology, 19(4), 544-567. https://doi.org/10.1521/jscp.2000.19.4.544

Goodenow, C. (1993). The Psychological Sense of School Membership Among Adolescents: Scale Development and Educational Correlates. Psychology in the Schools, 30(1), 79-90. https://doi.org/10.1002/1520-6807(199301)30:1<79::AID-PITS2310300113>3.0.CO;2-X

Gould, D., \& Petlichkoff, L. (1988). Participation motivation and attrition in young athletes. In: Children in Sport (3rd ed.). Human Kinetics, 161-178.

Gummadam, P., Pittman, L. D., \& Ioffe, M. (2016). School Belonging, Ethnic Identity, and Psychological Adjustment among Ethnic Minority College Students. Journal of Experimental Education, 84(2), 289-306. https://doi.org/10.1080/00220973.2015.1048844

Hagerty, B. M., Williams, R. A., Coyne, J. C., \& Early, M. R. (1996). Sense of belonging and indicators of social and psychological functioning. Archives of psychiatric nursing, 10(4), 235-244. https://doi.org/10.1016/S0883-9417(96)80029-X

Han, C. W., Farruggia, S. P., \& Moss, T. P. (2017). Effects of Academic Mindsets on College Students' Achievement and Retention. Journal of College Student Development, 58(8), 1119-1134. https://doi.org/10.1353/csd.2017.0089

Haskell, W. L., Lee, I. M., Pate, R. R., Powell, K. E., Blair, S. N., Franklin, B. A., \& Bauman, A. (2007). Physical activity and public health: updated recommendation for adults from the American College of Sports Medicine and the American Heart Association. Circulation, 116(9), 1081.

https://doi.org/10.1161/CIRCULATIONAHA.107.185649

Hausmann, L. R., Schofield, J. W., \& Woods, R. L. (2007). Sense of belonging as a predictor of intentions to persist among African American and White first-year college students. Research in higher education, 48(7), 803-839. https://doi.org/10.1007/s11162-007-9052-9

Hoffman, M., Richmond, J., Morrow, J., \& Salomone, K. (2002). Investigating "sense of belonging" in first year college students. Journal of College Student Retention: Research, Theory \& Practice, 4(3), 227-256. https://doi.org/10.2190/DRYC-CXQ9-JQ8V-HT4V

Homan, K. J., \& Tylka, T. L. (2014). Appearance-based exercise motivation moderates the relationship between exercise frequency and positive body image. Body Image, 11(2), 101-108. https://doi.org/10.1016/j.bodyim.2014.01.003

Huberty, J. L., Ransdell, L.B., Sigman, C., Flohr, J. A., Schult, B., Grosshans, O., \& Durrant, L. (2008). Explaining long-term exercise adherence in women who complete a structured exercise program. Research Quarterly for Exercise and Sport, 79(3), 374-384. https://doi.org/10.1080/02701367.2008.10599501

Huynh, V. W., \& Gillen-O'Neel, C. (2016). Discrimination and sleep: The protective role of school belonging. Youth \& Society, 48(5), 649-672. https://doi.org/10.1177/0044118X13506720

Karcher, M. J. (2004). Connectedness and school violence: A framework for developmental interventions. In E. Gerler (Ed.), Handbook of school violence, 7-42. Binghamton, NY: Haworth Press.

Li, F. (1999). The exercise motivation scale: Its multifaceted structure and construct validity. Journal of applied sport psychology, 11(1), 97-115. https://doi.org/10.1080/10413209908402953

Lowery, S. E., Kurpius, S. E. R., Befort, C., Blanks, E. H., Sollenberger, S., Nicpon, M. F., \& Huser, L. (2005). Body image, self-esteem, and health-related behaviors among male and female first year college students. Journal of College Student Development, 46(6), 612-623. https://doi.org/10.1353/csd.2005.0062

Lowry, R., Galuska, D. A., Fulton, J. E., Wechsler, H., Kann, L., \& Collins, J. L. (2000). Physical activity, food choice, and weight management goals and practices among US college students. American journal of preventive medicine, 18(1), 18-27. https://doi.org/10.1016/S0749-3797(99)00107-5

MacKinnon, D. P., Warsi, G., \& Dwyer, J. H. (1995). A simulation study of mediated effect measures. Multivariate 
behavioral research, 30(1), 41-62. https://doi.org/10.1207/s15327906mbr3001_3

Markland, D., \& Ingledew, D. K. (1997). The measurement of exercise motives: Factorial validity and invariance across gender of a revised Exercise Motivations Inventory. British Journal of Health Psychology, 2(4), 361-376. https://doi.org/10.1111/j.2044-8287.1997.tb00549.x

Matsumoto, H., \& Takenaka, K. (2004). Motivational profiles and stages of exercise behavior change. International Journal of Sport and Health Science, 2, 89-96. https://doi.org/10.5432/ijshs.2.89

Micari, M., \& Pazos, P. (2012). Connecting to the professor: Impact of the student-faculty relationship in a highly challenging course. College Teaching, 60(2), 41-47. https://doi.org/10.1080/87567555.2011.627576

Penedo, F. J., \& Dahn, J. R. (2005). Exercise and well-being: a review of mental and physicalhealth benefits associated with physical activity. Current opinion in psychiatry, 18(2), 189-193. https://doi.org/10.1097/00001504-200503000-00013

Perry, R. P., Hladkyj, S., Pekrun, R. H., \& Pelletier, S. T. (2001). Academic control and action control in the achievement of college students: A longitudinal field study. Journal of educational psychology, 93(4), 776. https://doi.org/10.1037/0022-0663.93.4.776

Rutter, L. A., Weatherill, R. P., \& Krill, S. C. (2013). Posttraumatic stress disorder symptoms, depressive symptoms, exercise, and health in college students. Psychological Trauma, 5(1), 56-61. https://doi.org/10.1037/a0021996

Ryan, R. M., \& Patrick, H. (2009). Self-determination theory and physical. Hellenic journal of psychology, 6, 107-124.

Ryan, R. M., Kuhl, J., \& Deci, E. L. (1997). Nature and autonomy: An organizational view of social and neurobiological aspects of self-regulation in behavior and development. Development and psychopathology, 9(4), 701-728. https://doi.org/10.1017/S0954579497001405

Seguin, R. A., Economos, C. D., Palombo, R., Hyatt, R., Kuder, J., \& Nelson, M. E. (2010). Strength training and older women: A cross-sectional study examining factors related to exercise adherence. Journal of Aging and Physical Activity, 18(2), 201- 218. https://doi.org/10.1123/japa.18.2.201

Silverman, M. M., Meyer, P. M., Sloane, F. et al. (1997). The Big Ten Student Suicide Study: a 10-year study of suicides on midwestern university campuses. Suicide Life Threat Behav., 27, 285-303.

Slaten, C. D., Elison, Z. M., Deemer, E. D., Hughes, H. A., \& Shemwell, D. A. (2017). The Development and Validation of the University Belonging Questionnaire. The Journal of Experimental Education, 1-19. https://doi.org/10.1037/t75836-000

Slaten, C. D., Yough, M. S., Shemwell, D. A., Scalise, D. A., Elison, Z. M., \& Hughes, H. A. (2014). Eat, sleep, breathe, study: Understanding what it means to belong at a university from the student perspective. Excellence in Higher Education, 5(1), 1-5. https://doi.org/10.5195/EHE.2014.117

Sobel, M. E. (1982). Asymptotic confidence intervals for indirect effects in structural equation models. Sociological methodology, 13, 290-312. https://doi.org/10.2307/270723

Solberg, V. S., Gusavac, N., Hamann, T., Felch, J., Johnson, J., Lamborn, S., \& Torres, J. (1998). The Adaptive Success Identity Plan (ASIP): A career intervention for college students. The Career Development Quarterly, 47(1), 48-95. https://doi.org/10.1002/j.2161-0045.1998.tb00728.x

Solberg, V. S., O'Brien, K., Villareal, P., Kennel, R., \& Davis, B. (1993). Self-efficacy and Hispanic college students: Validation of the college self-efficacy instrument. Hispanic journal of behavioral sciences, 15(1), 80-95. https://doi.org/10.1177/07399863930151004

Strayhorn, T. L., Bie, F., Dorime-Williams, M. L., \& Williams, M. S. (2016). Measuring the influence of Native American college students' interactions with diverse others on sense of belonging. Journal of American Indian Education, 55(1), 49-73. https://doi.org/10.5749/jamerindieduc.55.1.0049

Suminski, R. R., Petosa, R., Utter, A. C., \& Zhang, J. J. (2002). Physical activity among ethnically diverse college students. Journal of American College Health, 51(2), 75-80. https://doi.org/10.1080/07448480209596333

Tao, S., Qi, D., Michael, W. P., Bruce, H., \& Mark, P. S. (2000). Socia Support: Relations to Coping and Adjustment During the Transition to University in the People's Republic of China. Journal of Adolescent Research, 15(1), 123-144. https://doi.org/10.1177/0743558400151007

Teixeira, P. J., Carraça, E. V., Markland, D., Silva, M. N., \& Ryan, R. M. (2012). Exercise, physical activity, and self-determination theory: a systematic review. International Journal of Behavioral Nutrition and Physical Activity, 9(1), 78. https://doi.org/10.1186/1479-5868-9-78 
Thogersen-Ntoumani C., \& Ntoumanis, N. (2006). The role of self-determined motivation in the understanding of exercise-related behaviours, cognitions and physical self-evaluations. Journal of Sports Science, 24, 393-404. https://doi.org/10.1080/02640410500131670

Tinto, V. (1975). Dropout from higher education: A theoretical synthesis of recent research. Review of educational research, 45(1), 89-125. https://doi.org/10.3102/00346543045001089

Vartanian, L. R., Wharton, C. M., \& Green, E. B. (2012). Appearance vs. health motives for exercise and for weight loss. Psychology of Sport and Exercise, 13(3), 251-256. https://doi.org/10.1016/j.psychsport.2011.12.005

Wallace, L. S, Buckworth, J., Kirby, T. E., \& Sherman, W. M. (2000). Characteristics of exercise behavior among college students: application of social cognitive theory to predicting stage of change. Prev Med., 31, 494-505. https://doi.org/10.1006/pmed.2000.0736

Walton, G. M., \& Cohen, G. L. (2007). A question of belonging: Race, social fit, and achievement. Journal of Personality and Social Psychology, 92(1), 82. https://doi.org/10.1037/0022-3514.92.1.82

Walton, G. M., Logel, C., Peach, J. M., Spencer, S. J., \& Zanna, M. P. (2015). Two brief interventions to mitigate a "chilly climate" transform women's experience, relationships, and achievement in engineering. Journal of Educational Psychology, 107(2), 468. https://doi.org/10.1037/a0037461

Wilson, K., \& Brookfield, D. (2009). Effect of goal setting on motivation and adherence in a six week exercise program. International Journal of Sport and Exercise Psychology, 7(1), 89-100. https://doi.org/10.1080/1612197X.2009.9671894

Wolf, D. A. P. S., Perkins, J., Butler-Barnes, S. T., \& Walker Jr, T. A. (2017). Social Belonging and College Retention: Results From a Quasi-Experimental Pilot Study. Journal of College Student Development, 58(5), 777-782. https://doi.org/10.1353/csd.2017.0060

Zimmerman, B. J. (1996, April). Measuring and mis-measuring academic self-efficacy: Dimensions, problems, and misconceptions. Symposium presented at the meeting of the American Educational Association, New York.

Zumbrunn, S., McKim, C., Buhs, E., \& Hawley, L. R. (2014). Support, belonging, motivation, and engagement in the college classroom: A mixed method study. Instructional Science, 42(5), 661-684. https://doi.org/10.1007/s11251-014-9310-0

\section{Copyrights}

Copyright for this article is retained by the author(s), with first publication rights granted to the journal.

This is an open-access article distributed under the terms and conditions of the Creative Commons Attribution license which permits unrestricted use, distribution, and reproduction in any medium, provided the original work is properly cited. 